\title{
Mobile Ad Hoc Network Routing Protocols - Using OPNET Simulator
}

\author{
Madhavi S. Avhankar \\ Computer Science \\ Indira College of Commerce and Science \\ Pune, Maharashtra, Indialine 3: City, \\ Country \\ Madhavi.avhankar@gmail.com \\ Snehankita Majalekar \\ Computer Science \\ Indira College of Commerce and Science \\ Pune, Maharashtra, India \\ Snehankita.majalekar@gmail.com
}

\author{
Dr. Janardan A. Pawar \\ Computer Science \\ Indira College of Commerce and Science \\ Pune, Maharashtra, Indialine 3: City, \\ Country \\ janardanp@gmail.com \\ Suwarna Kedari \\ Computer Science \\ Indira College of Commerce and Science \\ Pune, Maharashtra, India \\ suwarna.kedari@gmail.com
}

\begin{abstract}
Mobile Ad Hoc Networks have evolved rapidly and are finding numerous applications in the areas of selfcreating, self-organizing and self-administering wireless networks. The present paper describes use of and comparison of three routing protocols. The parameters used for comparison are throughput and delay in response by varying the number of mobile nodes. A random waypoint mobility model was used for fixing the mobile nodes. The simulation study is carried out using OPNET modeler 14.5. Simulation result shows that for increasing number of mobile nodes OLSR offers better throughput and minimum delay than AODV and GRP routing protocols.
\end{abstract}

Keywords-MANET, OPNET, Routing Protocols, throughput, delay.

\section{INTRODUCTION}

MANET Mobile Ad hoc network [1] is a way to communicate different mobile device without any central administration or infrastructure. This property of MANET makes it unique and different among all other networks. The major challenges of Mobile Ad hoc networks are dynamic topology, radio communicating for multi-hop communication, bandwidth limitation, frequently breakage of links [2], power and resource constraint [3], physical security, network control without centralised access etc [4].

As MANET networks forms autonomous and communicating in an infrastructure less environment, they are gaining importance with huge number of applications in the commercial, military and private sectors.

Various routing protocols have been designed to exchange the information between different MANET nodes. Efficient routing protocols are key components of successful, reliable and proficient communications. These protocols are classified into three categories. Proactive or Table-driven routing protocols, Reactive or On-demand routing protocols and Hybrid (both proactive and reactive) routing protocols.
In reactive routing approach, a routing protocol does not take the initiative for finding a route to a destination, until it is required, resulting less overhead of control traffic [5]. E.g. AODV [6], DSR [7]. On the other hand, Proactive protocols mainly concern to provide route immediately as and when needed and are based on timely exchange of control messages for route discovery and maintenance. To send frequent updates of topology proactive routing protocol uses most of the bandwidth of the network. [8]. The examples of this kind of protocols are OLSR [9], DSDV [10] etc. Hybrid MANET protocols combine the features of both the classes i.e table driven and on demand. These category protocols keep route available for some destination all the time as like proactive feature and discovers the route for other destination only when it is required as like reactive protocol feature. ZRP [11], GRP [12] and TORA are the examples of hybrid protocols. To better understanding and utilization of the routing protocols it important to study and compared various routing protocols from different category.

OPNET

OPNET is one of the general-purpose simulator tool, build to check the performance of networking projects. It has some 
unique features like it provides Graphical User Interface for analysing, debugging and to simplify many tasks of simulation process. OPNET is a discrete event, object oriented commercial simulator. Though it is commercial, free licence tool is available for educational purpose [13]. OPNET simulator also allows the features like personalised presentation during runtime, addition of new models that are specific to the infrastructure to simulate etc, [14].

There are many reports in on using NS2 simulator for evaluating the performance of variety of routing protocols for MANET. However very few works have been done to evaluate the performance of routing protocols for MANET using OPNET modeler which provides very good GUI interface and programming tools which are very helpful to the researcher to do the simulation.

This paper discussed the most widely used three routing protocols of MANET and compared the performance using varying number of mobile nodes $(25,50,75$ and 100) using end to end delay and throughput performance matrices.

The rest of the paper is organized as follows: Overview of Mobile Ad hoc network routing protocols discussed in Section 2. Section 3 describes the Simulation Environment studied. Section 4 gives the analysis of results and discussion. Section 5 concludes this paper.

\section{OVERVIEW OF ROUTING PROTOCOLS}

Routing protocols in MANET are categories into three types - Table Driven, On-Demand and Hybrid. In this paper we have considered the most popular protocols among these three types.

This section briefly describes the algorithms AODV, OLSR and GRP protocols.

\section{AODV Routing Protocol}

AODV falls under category of on-demand routing protocol. AODV starts building of the route from source to destination only if it required by source node. This strategy comparatively reduces the control overhead. Types of messages or packets for routing in AODV are - RREQ (Route Request Packet), RREP (Route Response Packet), RERR (Route Error Packet) and Hello message packet [15]. As per an RFC document [16], the AODV uses two phases for routing purpose - Route Discovery Phase and Route Maintenance phase. In the route discovery phase the path from source to destination will be discovered and transmission begins. In the maintenance the algorithm takes care of the route repair $[17,18]$. The same has been described in algorithmic steps Figure 1.

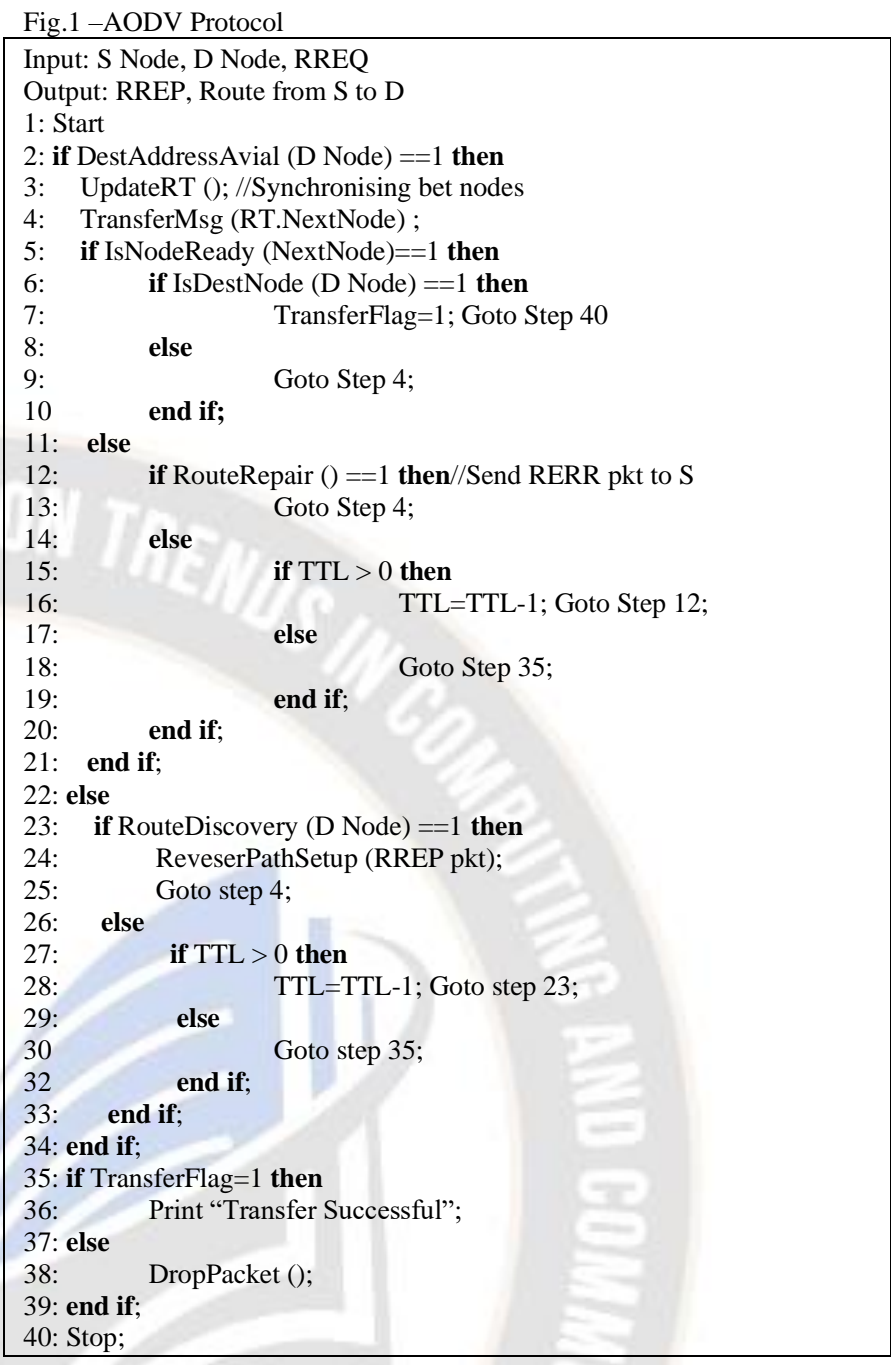

The algorithm exhibits a loop free processing and ensures freshness of route through the use of sequence number [17]. AODV can also support both multicasting and unicasting within unchanging framework. AODV protocol provides the facility of timer to expire the life time of route to maintain only fresh route in the table. AODV also has a challenge in Route discovery process might hamper optimal path discovery due to traffic overhead. Also congestion control and avoidance methods are not present in AODV to balance the traffic load [19.]. The delivery ratio of AODV can drop dramatically as number of connection increases [20].

OLSR protocol:

OLSR routing protocol of MANET is proactive in nature, i.e. it provides the route to the nodes in the network as and when needed [21]. OLSR inherits its basic properties from Link State Routing (LSR) protocol. It provides optimization to this LSR through a concept known as MPR (MutiPoint Relay). MPR are the nodes choose to flood the link state information to all other nodes within the network [22]. Use of MPR considerably reduces the control overhead compared to classical flooding mechanism. As OLSR is periodic in nature Route Construction process continuously going on to available routes as and when needed to every node. [23][24]. 
OLSR routing protocol can be described in three stages.

Figure 2(a), 2(b) and 2(c) describes these steps. In Fig.2(a) each node discovers the path from every other node in the network. While it discovers the path MPR helps the nodes to flood the link state information to all other nodes within the network. Fig 2(b). Fib 2(c) will takes care of message transmission in case required.

Types of messages/packets used in OLSR are - Hello packets, Topology control Packets and MID packets.

Algorithmic steps for OLSR are as follows.

Fig.2 (a) OLSR Protocol

Input: Hello pkts, Topology Control Pkts, MID pkts

Output: Generate Hello, TC and MID pkts, Route for each node

1: Start

2: for each node $\mathbf{N}$ in network

Broadcast Hello msg-received by all neighbour nodes ' $n$ '

if node ' $n$ ' receives Hello msg then

Process Link Sensing.

Construct/update MPR Selector table;

if MPR set available then

Generate TC_msg;

if change encounter then

Increment seq. no.;

Generate TC_msg;

Broadcast TC_msg through MPR

if $\mathbf{T C}$ _msg covers entire network then

if node receives $T T_{-}$msg then

if new info received then

- $=$ Update RT;

else

Update time

end if;

else

Delete stale entry; end if;

else

Generate TC_msg;

Goto step 13;

end if;

else

Update RT;

Advertise the new entry if any; end if;

Keep sending "Hello Pkts" periodically;

else

Stop forwarding TC-msg;

Goto step 2:

end if;

38: Stop.

Fig. 2(b) - MPR Nodes selection Algorithm

Input: Node $\mathrm{N}$ of OLSR Protocol

Output: MPR selection set for Node $\mathrm{n}$

1: Start

2: Identify all nodes set as $\mathrm{N} 1$ : neighbours of node $\mathrm{N}$;

3: Identify all nodes set as $\mathrm{N} 2$ : Strict 2-hop neighbours of N;

4 : Add rows to the MPR set for those nodes in N1 which are the only nodes to provide highest reachability to node in $\mathrm{N} 2$;

5: Stop

Once the route discovery process is complete, then any node in network can transfer packets to any another node through Packet Forwarding Algorithm described in Fig.2(c).

Fig. 2(c) - Packet Forwarding Algorithm from S to D in OLSR

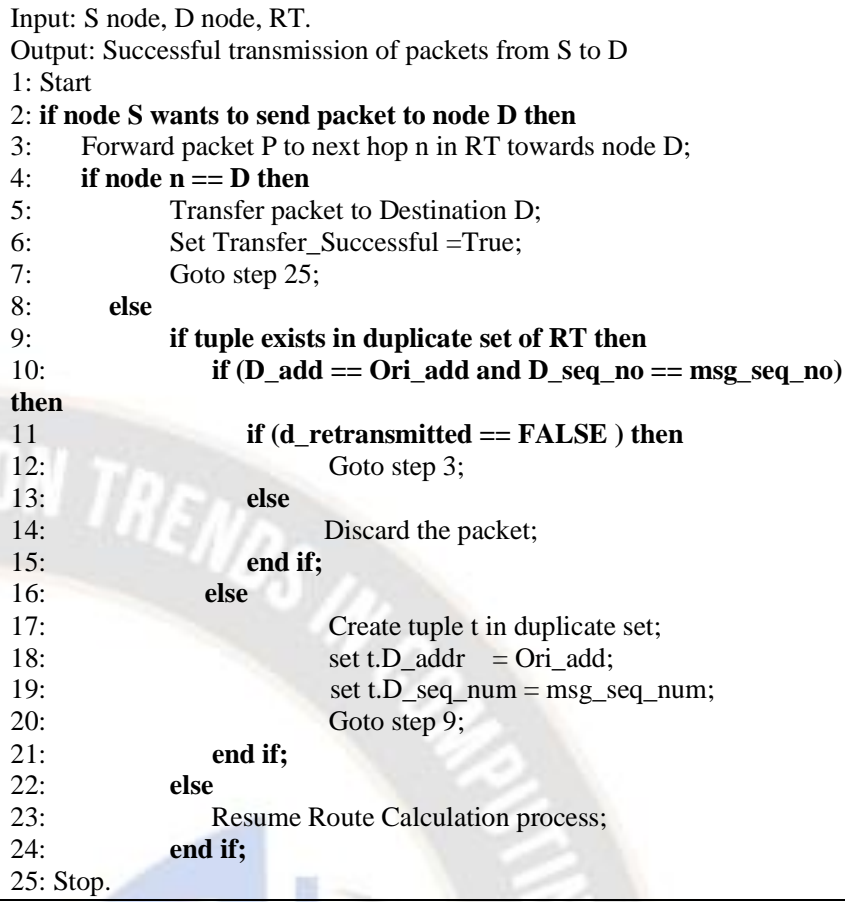

Flooding in OLSR minimized through the use of MPR nodes. Link reliability does not require in OLSR protocol as every node sends packets periodically and sequential delivery does not matter. OLSR protocol is best suited for dense network. An increase in number of mobile nodes causes to increase in number of control overhead messages. OLSR requires considerable amount of time to rediscover the broken link. OLSR require more processing power than other protocols to maintain the information of both one-hop and two-hop neighbors.[25]

\section{GRP Protocol}

GRP is an OPNET's custom proactive routing protocol. Routing of GRP is based on shortest geographical distance. Though this protocol falls under proactive category, source node can initiate the process of route discovery if route is not available to the destination. This approach of GRP comes under hybrid routing protocol. In GRP, position of each node is marked by Global Positioning System and flooding optimization is done using quadrant scheme. Size of quadrant is custom built. Hello protocol is used by every node to list all the neighbors.

One of the important concept known as backtracking is used by GRP for blocked routes [12]. Algorithmic steps for GRP are as shown in Fib 3.

GRP gives better performance through the use of backtracking. Global Positioning System gives exact position of nodes in GRP. But for shorter interval GRP may work in reverse manner. Packets dropping rate may increase as blocked routes are increased [26].

Fig. 3 GRP Protocol 


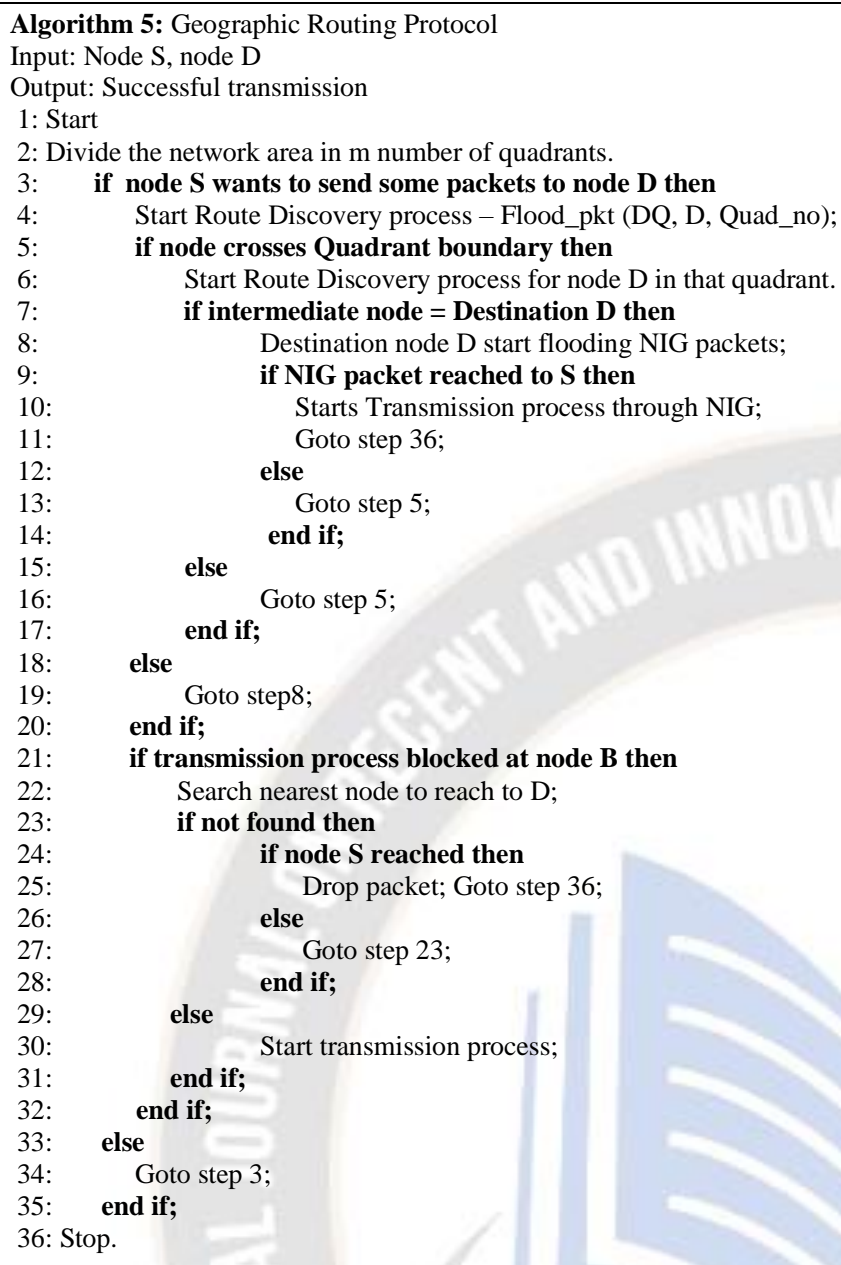

Table-1. Shows the characteristic comparison of above three MANET Routing Protocols (AODV, OLSR and GRP).

Table-1 - AODV, OLSR and GRP

\begin{tabular}{|l|l|l|l|}
\hline Parameter & AODV & OLSR & GRP \\
\hline $\begin{array}{l}\text { Network } \\
\text { Organization }\end{array}$ & Flat & Flat & $\begin{array}{l}\text { Flat } \\
\text { Hierarchical }\end{array}$ \\
\hline $\begin{array}{l}\text { Topology } \\
\text { dissemination }\end{array}$ & When required & Periodical & Both \\
\hline $\begin{array}{l}\text { Route } \\
\text { Availability }\end{array}$ & $\begin{array}{l}\text { Computed as per } \\
\text { need }\end{array}$ & $\begin{array}{l}\text { Always } \\
\text { available }\end{array}$ & Both \\
\hline $\begin{array}{l}\text { Communication } \\
\text { Overhead }\end{array}$ & Low & $\begin{array}{l}\text { Low because } \\
\text { of MPR }\end{array}$ & Medium \\
\hline Use of GPS & No & No & Yes \\
\hline $\begin{array}{l}\text { Link Support } \\
\text { Status }\end{array}$ & Bidirectional & Unidirectional & Unidirectional \\
\hline $\begin{array}{l}\text { Flooding } \\
\text { Mechanism }\end{array}$ & $\begin{array}{l}\text { Broadcasting to } \\
\text { every node }\end{array}$ & $\begin{array}{l}\text { Use of MPR } \\
\text { for flooding }\end{array}$ & $\begin{array}{l}\text { Flooding } \\
\text { within } \\
\text { Quadrant }\end{array}$ \\
\hline Packets Used & $\begin{array}{l}\text { RREQ Packet, } \\
\text { RREP Packet, } \\
\text { RERR Packet } \\
\text { Hello Packet. }\end{array}$ & $\begin{array}{l}\text { Hello Packet, } \\
\text { Topology } \\
\text { Control } \\
\text { Packet, MID } \\
\text { Packet. }\end{array}$ & $\begin{array}{l}\text { Hello packet, } \\
\text { Backtrack } \\
\text { packet }\end{array}$ \\
\hline
\end{tabular}

\section{SIMULATION PARAMETERS AND SETUP}

OPNET (modeler 14.5) simulator is used for simulation. Simulation experiments were conducted for three MANET routing protocols (AODV, GRP and OLSR) by varying number of mobile nodes $(25,50,75$ and 100$)$ on $5 \mathrm{kmX} 5 \mathrm{~km}$ fixed sized network. Every mobile node supports transmission data rate of $11 \mathrm{Mbps}$, generating packets of 1024 bytes, after every 2 seconds. Random Waypoint (RWP) mobility model is used for defining mobility pattern of nodes. Mobile nodes are moving at 10 meters/sec speed. Table-2 contains simulation parameters, Table- 3 is the traffic generation parameters and Table-4 shows mobility configuration parameters.

Table-2: Simulation Parameters

\begin{tabular}{|l|l|l|}
\hline SNo & Parameter & Value \\
\hline 1 & Number of Mobile Nodes & $25,50,75$ and 100 \\
\hline 2 & Campus Network Size & $5 \mathrm{KmX5Km}$ \\
\hline 3 & Routing Protocols & AODV, GRP and OLSR \\
\hline 4 & Simulation Time & 5 Minutes \\
\hline
\end{tabular}

Table-3: Traffic Generation Parameters

\begin{tabular}{|l|l|l|}
\hline SNo & Parameter & Value \\
\hline 1 & Traffic Start Time (seconds) & 1.0 \\
\hline 2 & Packet Inter-arrival Time (Seconds) & 2 \\
\hline 3 & Packet Size (bytes) & 1024 \\
\hline 4 & Traffic Stop Time (seconds) & End of Simulation \\
\hline 5 & Transmission Data Rate (Mbps) & 11 \\
\hline \multicolumn{3}{|c|}{ Table-4: Mobility Configuration Parameters } \\
\begin{tabular}{|l|l|l|}
\hline SNo & Parameter & Value \\
\hline 1 & Mobility Model & Random Waypoint \\
\hline 2 & Speed (meters/seconds) & 10 \\
\hline 3 & Pause Time (Seconds) & 10 \\
\hline 4 & Start Time (Seconds) & 10 \\
\hline 5 & Stop Time (Seconds) & End of Simulation \\
\hline
\end{tabular}
\end{tabular}

\section{RESULT ANALYSIS AND DISCUSSION}

The performance of three MANET routing protocols AODV, GRP and OLSR are compared based on throughput and delay by varying number of mobile nodes.

a) Throughput comparison

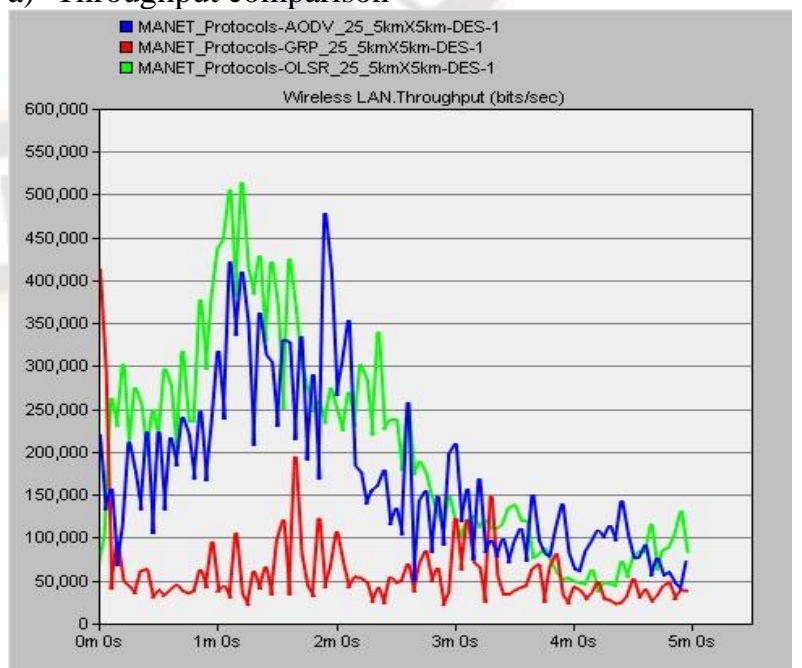

Figure-4 Throughput comparison of three networks running AODV, GRP, OLSR routing Protocols with each network containing 25 mobile nodes. 


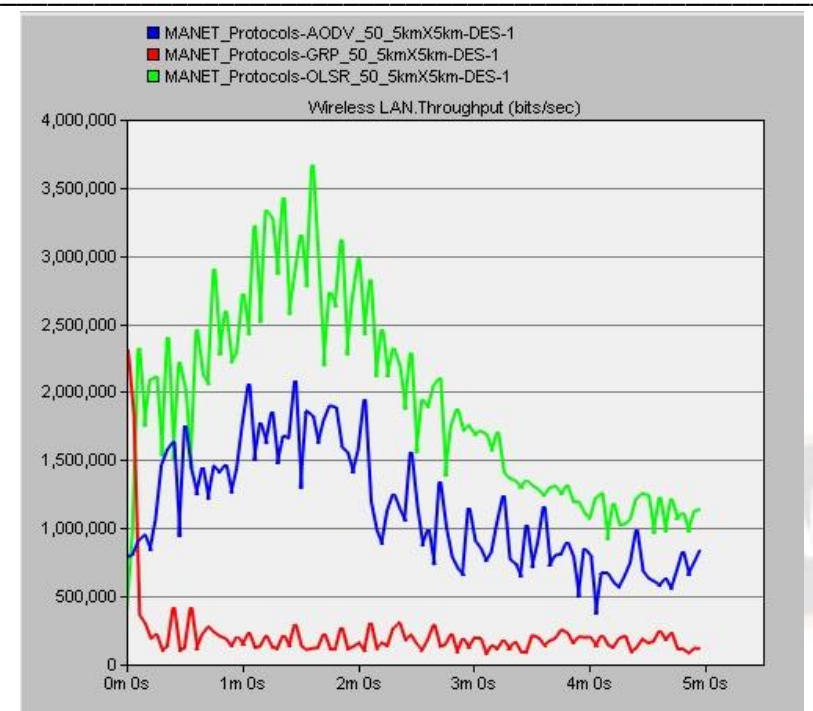

Figure-5: Throughput comparison of three networks running AODV, GRP, OLSR routing Protocols with each network containing 50 mobile nodes.

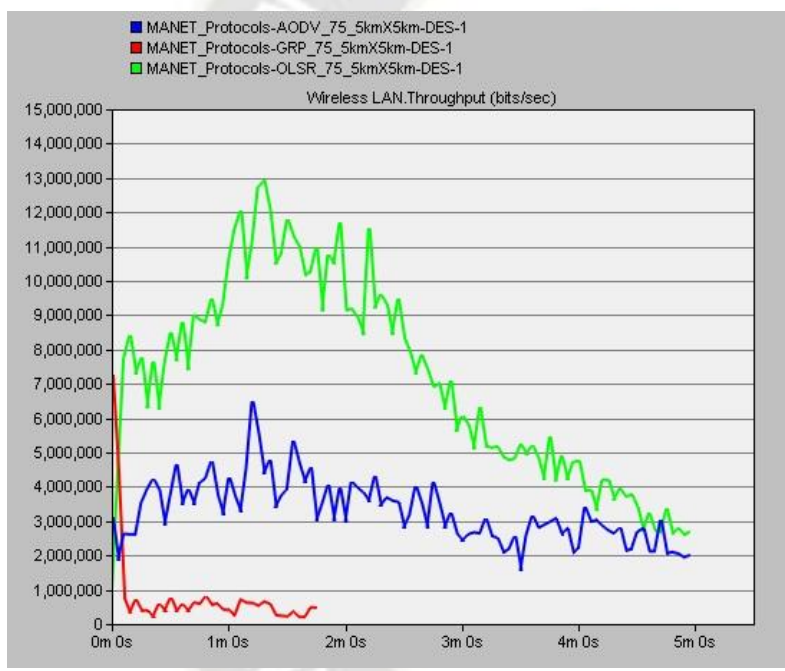

Figure-6: Throughput comparison of three networks running AODV, GRP, OLSR routing Protocols with each network containing 75 mobile nodes.

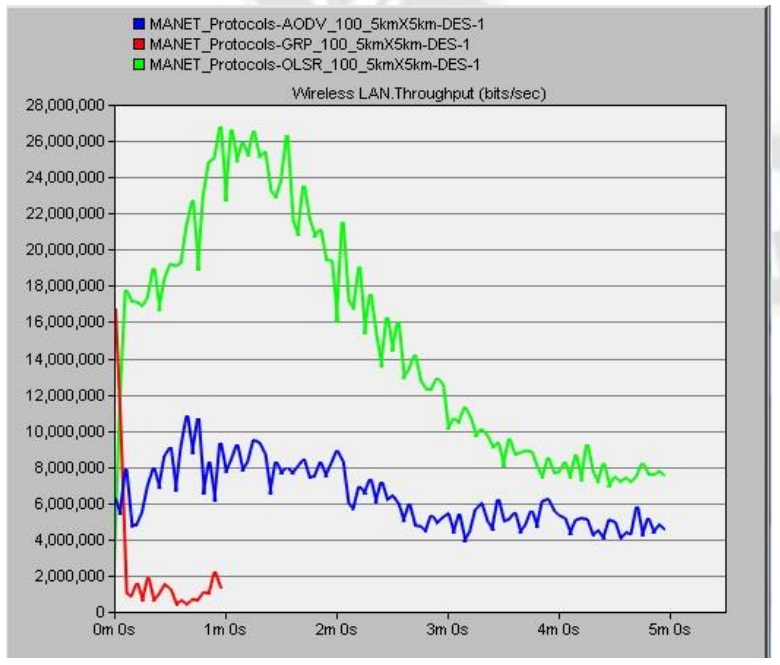

Figure-7: Throughput comparison of three networks running AODV, GRP, OLSR routing Protocols with each network containing 100 mobile nodes.
Fig. 4-7 gave a comparison between number of packets sent per unit time-Throughput versus number of nodes.

The throughput (Mbps) comparison of AODV, GRP and OLSR networks for varying number of mobile nodes is given in Figure-8.

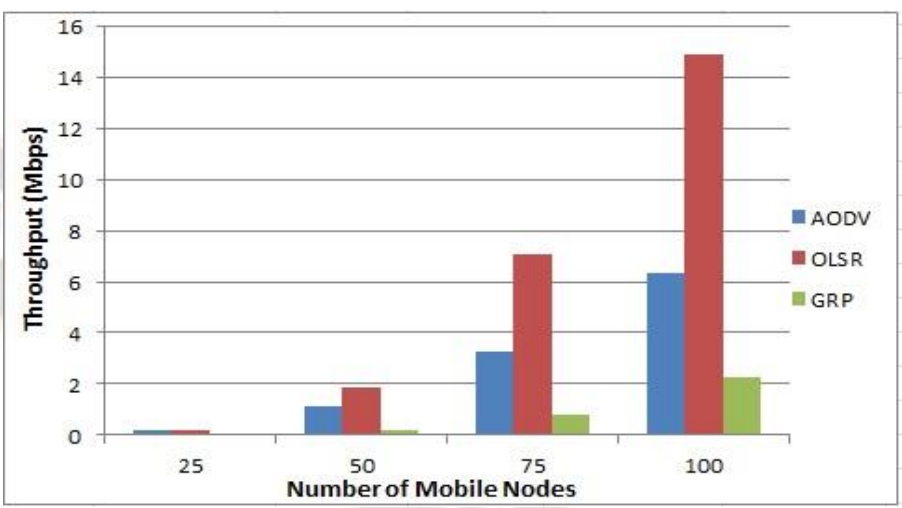

Figure-8: The throughput (Mbps) comparison of AODV, GRP and OLSR Networks for varying number of mobile nodes

It was observed that, both AODV and OLSR offer approximately same and better throughput than GRP when network containing 25 mobile nodes. Figure- 8 shows that throughput offered by OLSR is increasing extensively with increasing number of mobile nodes.

b) Delay comparison:

Fig. 9 and 10 compares the delay of three network protocols for 25 nodes and 100 respectively.

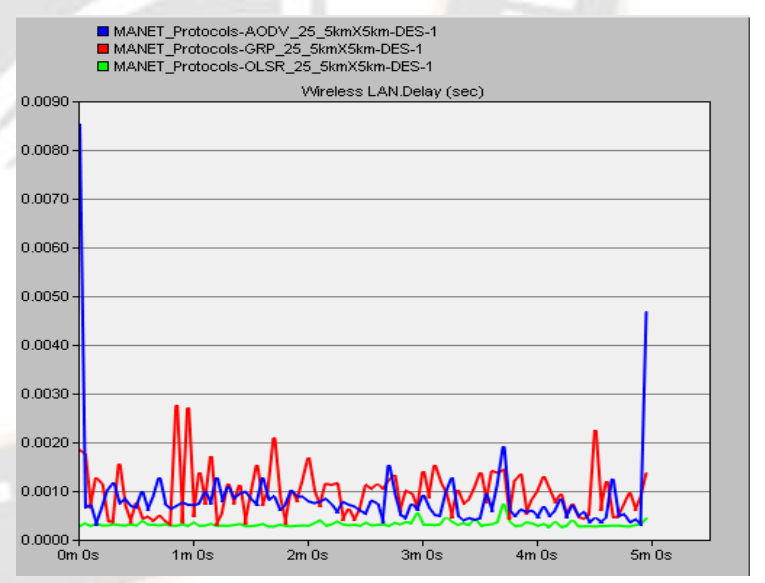

Figure-9: Delay comparison of three networks running AODV, GRP, OLSR routing Protocols with each network containing 25 mobile nodes. 


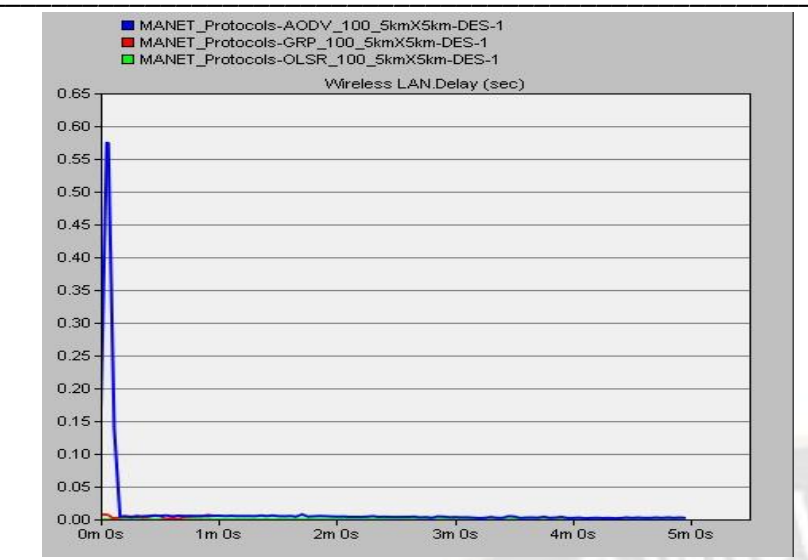

Figure-10: Delay comparison of three networks running AODV, GRP, OLSR routing Protocols with each network containing 100 mobile nodes.

The delay (seconds) comparison of AODV, GRP and OLSR networks for varying number of mobile nodes is given in Figure-11.

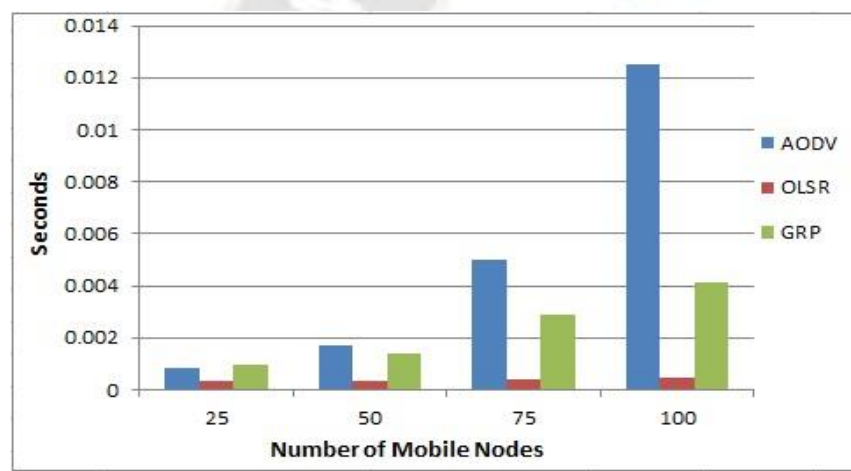

Figure-11: The delay (seconds) comparison of AODV, GRP and OLSR Networks for varying number of mobile nodes

It was observed that, OLSR is offering minimum delay, i.e. for 25 mobile nodes. With increasing number of mobile nodes, delay of OLSR network approximately remains constant but delay of AODV and GRP network is increasing gradually.

\section{CONCLUSION}

This paper talks about three most widely used MANET routing protocols and compared the performance of these protocols by running those protocols over $5 \mathrm{Km}$ X $5 \mathrm{Km}$ fixed sized network with varying number of mobile nodes from 25 to 100 . These simulation experiments are performed on OPNET modeler 14.5. The simulation result shows that for increasing number of mobile nodes OLSR offers better throughput than AODV and GRP routing protocols. Also, OLSR protocol offers minimum delay than AODV and GRP routing protocols. Hence, this paper concludes that OLSR gives better performance than AODV and GRP for varying number of mobile nodes on fixed sized MANET.

The work done in this paper might be helpful for the researchers who wants to do research on mentioned protocols for MANET.

This paper can be enhanced by analysing and comparing these three protocols (ADOV, OLSR and GRP) under different mobility model and different type of traffic sources with respect to other performance metrics.

\section{REFERENCES}

[1] Shantaf, A. M., Kurnaz, S., \& Mohammed, A. H. (2020, June). Performance Evaluation of Three Mobile Ad-hoc Network Routing Protocols in Different Environments. In 2020 International Congress on Human-Computer Interaction, Optimization and Robotic Applications (HORA) (pp. 1-6). IEEE..

[2] Conti, M., \& Giordano, S. (2014). Mobile ad hoc networking: milestones, challenges, and new research directions. IEEE Communications Magazine, 52(1), 8596.

[3] Tamilarasan, S. (2011). A comparative study of multihop wireless ad-hoc network routing protocols in manet. International Journal of Computer Science Issues (IJCSI), 8(5), 176.

[4] Kumar, S., \& Kumar, J. (2012). Comparative analysis of proactive and reactive routing protocols in mobile adhoc networks (manet). Journal of Information and Operations Management, 3(1), 92.

[5] Abolhasan, M., Wysocki, T., \& Dutkiewicz, E. (2004). A review of routing protocols for mobile ad hoc networks. Ad hoc networks, 2(1), 1-22.

[6] Perkins, C., Belding-Royer, E., \& Das, S. (2003). Ad hoc on-demand distance vector (AODV) routing (No. RFC 3561).

[7] Johnson, D. B., \& Maltz, D. A. (1996). Dynamic source routing in ad hoc wireless networks. In Mobile computing (pp. 153-181). Springer, Boston, MA.

[8] Royer, E. M., \& Toh, C. K. (1999). A review of current routing protocols for ad hoc mobile wireless networks. IEEE personal communications, 6(2), 46-55.

[9] Jacquet, P., Muhlethaler, P., Clausen, T., Laouiti, A., Qayyum, A., \& Viennot, L. (2001). Optimized link state routing protocol for ad hoc networks. In Multi Topic Conference, 2001. IEEE INMIC 2001 (pp. 62-68). IEEE.

[10] Perkins, C. E., \& Bhagwat, P. (1994, October). Highly dynamic destination-sequenced distance-vector routing (DSDV) for mobile computers. In ACM SIGCOMM computer communication review (Vol. 24, No. 4, pp. 234-244). ACM.

[11] Beijar, N. (2002). Zone routing protocol (ZRP). Networking Laboratory, Helsinki University of Technology, Finland, 9, 1-12.

[12]Zhiyuan, L. (2009, October). Geographic routing protocol and simulation. In 2009 Second International Workshop on Computer Science and Engineering (Vol. 2, pp. 404-407). IEEE.

[13] Prokkola, J. (2006). Opnet-network simulator. URL http://www. telecomlab. oulu. fi/kurssit/521365A tietoliikennetekniikan simuloinnit ja tyokalut/Opnet esittely, 7.

[14] Köksal, M. (2008). A survey of network simulators supporting wireless networks. línea: http://www. ceng. metu. edu. tr/ e1595354/A\% 20Survey, 20. 
[15] Desai, R., \& Patil, B. P. (2014, April). Analysis of routing protocols for Ad Hoc Networks. In 2014 International Conference on Circuits, Systems, Communication and Information Technology Applications (CSCITA) (pp. 111-115). IEEE

[16] Moudni, H., Er-rouidi, M., Mouncif, H., \& El Hadadi, B. (2016, May). Performance analysis of AODV routing protocol in MANET under the influence of routing attacks. In 2016 International Conference on Electrical and Information Technologies (ICEIT) (pp. 536-542). IEEE.

[17] Royer, E. M., \& Perkins, C. E. (1999, February). Adhoc on-demand distance vector routing. In Proceedings of the 2nd IEEE Workshop on Mobile Computing Systems and Applications (Vol. 2, pp. 90-100).

[18] Perkins, C., Belding-Royer, E., \& Das, S. (2003). Ad hoc on-demand distance vector (AODV) routing (No. RFC 3561).

[19] Srikanth, V., Jeevan, A. C., Avinash, B., Kiran, T. S., \& Babu, S. S. (2010). A review of routing protocols in wireless mesh networks. International Journal of Computer Applications, 1(11).

[20] Lu, Y., Wang, W., Zhong, Y., \& Bhargava, B. (2003, March). Study of distance vector routing protocols for mobile ad hoc networks. In Proceedings of the First IEEE International Conference on Pervasive Computing and Communications, 2003.(PerCom 2003). (pp. 187-194). IEEE.
[21] Benzaid, M., Minet, P., \& Al Agha, K. (2002). Integrating fast mobility in the OLSR routing protocol. In 4th International Workshop on Mobile and Wireless Communications Network (pp. 217-221). IEEE.

[22] Qayyum, A., Viennot, L., \& Laouiti, A. (2002, January). Multipoint relaying for flooding broadcast messages in mobile wireless networks. In Proceedings of the 35th annual Hawaii international conference on system sciences (pp. 3866-3875). IEEE.

[23] Clausen, T., \& Jacquet, P. (2003). Optimized link state routing protocol (OLSR) (No. RFC 3626).

[24] Jacquet, P., Muhlethaler, P., Clausen, T., Laouiti, A., Qayyum, A., \& Viennot, L. (2001). Optimized link state routing protocol for ad hoc networks. In Multi Topic Conference, 2001. IEEE INMIC 2001 (pp. 62-68). IEEE.

[25] Hassnawi, L. A., Ahmad, R. B., Yahya, A., Aljunid, S. A., \& Elshaikh, M. (2012). Performance analysis of various routing protocols for motorway surveillance system cameras' network. International Journal of Computer Science Issues (IJCSI), 9(2), 7.

[26] Mittal, P., Singh, P., \& Rani, S. (2013). Performance Analysis of AODV, OLSR, GRP and DSR Routing Protocols with Database Load in MANET. International Journal of Research in Engineering and Technology (IJRET), 2(09).. 